\title{
Genre Analysis : Investigation of the Functions of Simple Present and Simple Past Tenses in Translator's Introduction
}

\author{
Dr. Nasir Ali Osman Satti \\ Dept. of Languages \& Translation, Faculty of Education \& Arts, University of Tabuk, Tabuk, \\ Kingdom of Saudi Arabia
}

\begin{abstract}
The present paper aims to investigate the functions of tenses within the rhetorical moves of the translator's introduction collected from partial researches found in the Translation and Arabicization Unit in Khartoum University and written by M.A. Translation Program Students fulfilling the requirements of the M.A. in translation. It also aims to verify whether translator's introductions follow a certain tense aspect or not and how much tenses use and usage within moves coincide with Swales ( 1981b, 1985)and Bhatia ( 1993 ) Models . Concerning the data collection method, the sample of the study was collected randomly and manually consisting of 50 translator's introductions. As regards the data analysis method, the researcher used the qualitative method . He also employed the quantitative method and used the SPSS - 22 program to process the data .He sorted, coded and identified the tenses and categorized them in terms of form and functions depending on Swales genre Analysis model. The researcher came up with several results that can be summarized as follows. The results indicate that simple present tense performed certain functions in relation to and within certain moves. It frequented 34 times representing 58.62\% to perform the function of a technical definition of translation. The simple present also recurred 40 times representing $93 \%$ to describe the rationale of selecting the book for the translation. Again the simple present occurred 7 times with the frequency of $38.89 \%$ to indicate the difficulties the translators encountered since they decided to select a book. For the function of describing the method of translation, the simple present frequented 20 times recording $46.51 \%$. On the other hand the results indicate that simple past tense had certain uses in relation to and within moves. Concerning the definition move, simple past frequented 20 times representing 34.48\% to state a historical background of translation. Difficulties relating to conceptual aspects within the definition move frequented 22 times reporting $37.93 \%$. Moreover, simple past frequented 31 times registering $72.09 \%$ to show the action of the selection of the material to be translated. Again , as regards the method move, the results indicate the use of simple past frequented 3 times representing $6.98 \%$ to indicate the action of the selection of the method to be used in the translation, whereas the use of the past frequented 37 times recording $86.05 \%$ to express the steps adopted in the method of translation. In relation to the difficulty move, the past frequented 18 times with the percentage of $100 \%$ and the usage of simple past within such move showed no other uses. The researcher has observed the existence of a possible correlation between the functions of tenses and the steps of the moves therefore he recommends that further examination to be conducted on the steps which form the moves separately. The researcher also recommends that further investigation to be conducted on the relevance of tenses' functions to the steps of the moves.
\end{abstract}

Keywords: present, past, tense, move.

DOI: $10.7176 / \mathrm{JEP} / 10-3-06$

\section{1-Introduction}

John ( 2004 ) identified the primary purposes of language and confined them to communication and representation. He explained them in the quotation below:

" In Plato's Cratylus, Socrates says that the purpose of words is for discriminating things from one another, and for teaching each other about those things. Discriminating things from one another is what is meant by representation. Teaching each other about things is communication - where what is being communicated is , as it happens, representation. Socrates makes clear that communication is rather a poor and vulgar thing, whereas representation is a communion with the ideal forms of things as they exist in Heaven.

In 2300 years since Plato wrote the dialogue, linguists and philosophers have maintained essentially the same view . Communication has largely been taken for granted, and the important work to be done on language has been assumed to be the understanding of its functioning as a system of representation . Ludwig Wittgenstein ( $1889-1951$ ) led attempts to analyze the functioning of language as a system of representation until finally deciding that, ultimately, representation cannot be separated from communication. A language, he concluded, is nothing more nor less than the use to which it is put. "

Hunston and Francis ( 2000 ) note that Communication is achieved by means of syntactic units which are normally composed of units directly below them in the hierarch like phrases. There are functions that phrases may fulfil in clause structures; They are subject, verb, object., complement...etc. The verb function is always filled by a verb phrase; no other category of phrase ever operates in this function. It is virtually a defining characteristic of a clause that it contains a verb, either of finite or a non - finite kind. A finite form of the verb 
shows tense distinction between "past" and "present" tense. The grammatical category of tense is related to real world time. On the other hand most linguists have examined the question that the primary tenses in academic writing have a much more specialized set of interpretations than in the general language . For instance, Lackstrom et al . ( 1973 ) and Oster ( 1981 ) point out that Present Tense expresses universal laws, processes , repeated actions, definitions, descriptions and observations . Furthermore, Malcolm ( 1987 ) distinguishes between "the timeless " implied by Present Tense , and " time - boundedness " implied by Past Tense . ( 1987 : $38-40$ ). She argues that an important function of Past Tense is to focus on the experiment at hand, distinguishing between the objective experience of the researchers and the abstract, subjective ideas expressed by the Present Tense.

Moreover, Salager-Meyer's large-scale study of verb forms in Abstracts (1992) shows that PRES is used to emphasizes the relevance of previous research, whereas PAST indicates the undeveloped nature of previous findings. Tense emerges from these studies as a stable, but diffuses grammatical category which corresponds to various binary semantic divisions such as action / activity, designation / denotation, authorial stance / subject.. I want to argue, however, that our interpretation of an individual tense marker must also depend on the lexical pattern in which the tense is used, not to mention the surrounding textual role of the maker in relation to or in contrast with previous verb forms.

Again, studies on the distribution of tenses have also revealed a very complex picture. Halliday and Martin (1993) discuss the distribution of tenses in general and scientific English, noting that the PRES / PAST is the type of binary grammatical system in which one term is unmarked, with a stable ratio of distribution of around $90 \%: 10 \%$. But even if this ratio were stable in the scientific research article, the context of use does not have to be the same as in the general language. Much research has been done on the distribution of forms within the different sub-section of the research article, for example It It is worthmentioning that Barber (1962), Gerbert (1970), Hawes and Thomas (1997), Biber, Conrad and Reppen (1998) and White (2004 ). Heslot (1982)and Hanania \& Akhtar (1985) establish that while PRES is the key tense in Introduction / Discussion sections, the PAST becomes prevalent in Methods /Results. Swales (1990) presents a synthesis of work done on the distribution of tenses and other verb forms; including the passive (PASS). The following table sums up the relative frequency of verb forms according to Swales (1990: 105):

\begin{tabular}{|l|l|l|l|l|}
\hline & Introduction & Methods & Result & Discussion \\
\hline PRES & high & Low & High & High \\
\hline PAST & Mid & High & High & Mid \\
\hline PASS & low & High & variable & Variable \\
\hline
\end{tabular}

These data clearly belie the notion that grammatical features are evenly spread across the research article, a point that can be made about grammatical items as well (Gledhill 2000a,2000b), It is significant that Swales' explanation for the transition from one form to another in different sub-sections is couched in terms of proximity to the author's message (reported in Swales and Feak 1994: 184):

"The differences among ... tenses are subtle. In general, a move from past to present perfect and then to present indicates that the research reported is increasingly close to the writer in some way: close to the writer's own opinion, close to the writer's own research, or close to the current state of knowledge."

This is certainly a plausible account, and one that suggests a contrastive role for different verb forms. But Swales and Feak's view seems to contradict the conclusions of other linguists, namely that the PAST is closer to the research at hand. However, all of these researchers appear to share the view that the PRE and the PAST have reasonably predictable meanings even though, as we have seen, they are unable to pin them down. This also happens to the central assumption among discourse theorists (following Culioli 1999), who claims that grammatical forms are 'operators', units which have a fixed reference and represent traces of cognitive operations. According to this view, tense usage is the result of a mental computation, complete and invariable in its reference, regardless of context. Unfortunately, such theories do not get us any closer to understanding how the different parts of the clause combine in order to create a message (the notion of 'syntax' is notably opaque in Culioli's approach), and they certainly do not explain how tense operates as a textual level.

Christopher (2009a) believes It could be argued that the meanings that we commonly associate with PRES or PAST are contingent, and therefore our interpretation of them has just as much to do with the lexicogrammatical constructions in which they are used. This would account for the apparent 'specialization' of the PRES and PAST tenses in academic writing. Adamczewksi (1982: 150) makes a similar point about the grammatical uses of have, whose interpretation ultimately depends on context: ' 'Tout ce que I' on peut dire [ ... ] de tel out el employ de $H A V E$ n'est qu'un effet de I'interaction ave des marqueurs co-occurrents....' . In other words, grammatical forms only do half the work for us: they derive some if not most of their meaning from the typical constructions in which they are used. I discuss this 'contextualist' approach further in the discussion of colligation, below. However, before looking at colligation in detail, it is important to examine how tenses may vary within a single text. 


\section{2- Literature review.}

Several studies have been conducted in the field of genre analysis. This section aims to provide the previous studies relevant to the present investigation of functions of tenses in introductions and abstracts, in general, and translation - related introductions particularly. Bhatia ( 1993 :22) noted the necessity of acquiring some relevant knowledge on the text's subject and conventions. He suggested four different relevant subjects including literature on linguistic analyses of the genre and methods or theories of linguistic analysis.

Jittra ( 2016 ) analyzed and described English tenses used in an online news website and investigated which kinds of tenses are frequently used. The research instrument was a checklist which determines and categorizes English tenses as past tense, present tense and future tense. The results concluded by Jittra indicate that past tense frequented $56 \%$, present tense represented $43 \%$ and future tense recorded $1 \%$.

Moreover, Mahjoobeh ( 2015 ) examined 24 research article abstracts among English native speakers and non - native ( Iranian ) speakers in the field of electronic Engineering The analysis mainly focused on the rhetorical structure, i.e. the constituent moves, sub - moves . In addition, verb choices and the voice and tense of the verbs in move 2 and move 4 were investigated. The results show no major differences observed between non - native speakers and native present tense ( $91 \%$ and 95\%) which according to the researcher is a risky task in Santos ( 1996 )idea established knowledge speakers groups tense and voice preferences in move4, whereas in both categories there seems to be strong preference for.

Similarly, Ahmed ( 2011 ) investigated M.A. researches Abstracts . He found that there were four tenses used in writing abstracts, present simple tense, past perfect tense, past simple tense and passive tense. According to the researcher, the present simple tense recorded $45 \%$ with the frequency of 221 . Then, passive tense reported $41.1 \%$ and frequented 202 times. The past simple tense was less in percentage than the tense and it was $11 \%$ registering the frequency of 54 . The present perfect was the least used and made $2.9 \%$. He noted that present simple and passive tense made the most frequency .

In addition, Chodurova ( 2010 ) focused on the analysis of the language of British news paper in terms of distribution of tenses. The analysis compared differences between tenses used in broadsheets and tabloids, and also between printed and electronic version of news papers. The results of the study show that the main change in the tenses is connected with the present tense, which is a very universal tense and can be used partly for expressing the past, partly for the present and also for the future.

Finally, Christopher ( 2009a ) argued that the present and past tense are not just grammatical features which express ideational time - reference at the level of the clause. He also argued that tenses have colligations and found a very consistent correlation between tenses on the one hand and lexico -grammatical constructions .Such result motivated to the present researcher to conduct a detailed study on the functions of tenses as a basis for a forthcoming study on the steps of the rhetorical moves. Again Christopher found that present tense coincides with the expressions of qualitative " attribution ", empirical projection. Among the results he reached is the association of past tense with quantitative attribution and identification, as well as research - oriented projection and descriptive uses. These are eventually related to macro - genres which exist in more general forms of the language. Furthermore, the researcher found that the role of tenses in the language system cannot be disassociated from rhetorical constructions .

\section{3 - Statement of the problem.}

From his own experience in the field of teaching translation and supervising partial researches, the researcher has observed that the use of tenses in the translator's introductions varies from some students to others. On the other hand, the researcher has noticed that the uses of the tenses and their functions were typical sources of difficulty for some students. Therefore significance of the present investigation lies in the fact that its results may provide insights into the standardization of the tenses and their functions for the students who are required to write a translator's introduction, the translators and translation curricula designers, and writing skills instructors as well.

\section{4 - Research Objectives.}

The current study attempts to achieve the objectives below.

i- to investigate the frequencies and percentages of the tenses used in the translator's introductions by Khartoum University graduates of M.A. Translation program/

ii- to examine the functions of the tenses used in the translator's introductions written by Khartoum University graduates of M.A. Translation Program.

iii- to verify how much the frequency of tenses corresponds to Swales distribution of tenses ( 1990: $105)$.

\section{5- Research Questions.}

In order to achieve the research objectives, this study addresses the following research questions: 
i- What functions does simple present tense express within the definition move in the translator's introductions written by the M.A. translation program graduates of Khartoum University?

ii- What functions does simple present tense express within rationale move in the translator's introduction written by the M.A.Translation Program graduates of Khartoum University?

iii- What functions does simple present tense express within difficulties moves in the translator's introduction written by M.A. Translation Program graduates of Khartoum University?

iv- What functions does simple present tense express within method move in the translator's introductions written by M.A. Translation Program graduates of Khartoum University?

v- Do the frequency of such tenses correspond to Swales ( 1990 ) synthesis work done on tenses distribution?

vi- What functions does simple past tense express within the definition move in the translator's introduction written by M.A.Translation Program graduates of Khartoum University?

vii- What functions does simple past tense express within the rationale move in the translator's introduction written by M.A. Translation Program graduates of Khartoum University?

viii- What functions does simple past tense express within the difficulties move in the translator's introductions written by M.A. Translation Program graduates of Khartoum University?

ix- What functions does simple past tense express within the method move in the translator's introduction written by M.A.Translation Program graduates of Khartoum University?

\section{6- Research Method.}

Bhatia presented a genre analysis model for investigating genre. It comprises seven different steps which should be considered in connection with any kind of text. However, not all steps may be relevant for all texts . A relevant step for the current work is the analysis of lexico - grammatical features . This analysis focuses very strictly on the specific language features of the text and the method is to conduct a statistical survey of the common features in a text. Bhatia ( $1993: 25$ ) emphasized " the main purpose would be to confirm or disprove some of the statements we tend to make about ......various genre.

Concerning the data collection method, the sample of the data was representative consisting of 50 introductions collected randomly and manually from the Translation and Arabicization Unit, at the University of Khartoum for the academic years 1990s - 2013. As for the data analysis method, the researcher employed qualitative and quantitative methods. He used the PSSS - 22 version to process the data s. He identified, sorted and coded the tenses in terms of forms and use.

\section{7- Results and Discussion.}

One of the steps of Bhatia's Genre Analysis Model is the analysis of lexico - grammatical features This step employs statistical analysis. Similarly, McIntosh and Strevens ( 1964:87) stressed the frequency of the lexico grammatical features of a particular text - variety. They postulated that language varies as its function varies; it differs in different situations. The data of the current investigation collected from 50 Translator's Introductions were entered into SPSS - 22 and analyzed as the tables below present. Our general results in line with the research questions are presented below.

1- How many and what functions does the simple present tense express within the definition move? In order to investigate the first research question, which aims to find the types and frequency of functions expressed by simple present tense within the definition move, descriptive statistics were used to identify the frequency of the functions expressed. As shown in Figure 1, simple present tense performed certain functions in relation to and within certain moves. It frequented 34 times representing $58.62 \%$ to express the function of a technical definition of translation. However, the translators employed the simple present with the frequency of 12 times representing $20.69 \%$ to describe the style of the book, whereas the frequency of non represented $20.69 \%$ frequenting 12 times.

Table (1).Frequency and percentage of functions of simple present tense within definition move.

\begin{tabular}{|l|l|l|l|l|l|l|}
\hline Definition & Tech & DR & DM & SB & Non & Total \\
\hline Frequency & 34 & 0 & 0 & 12 & 12 & 58 \\
\hline Percentage & 58.62 & 0 & 0 & 20.69 & 20.69 & 100 \\
\hline
\end{tabular}




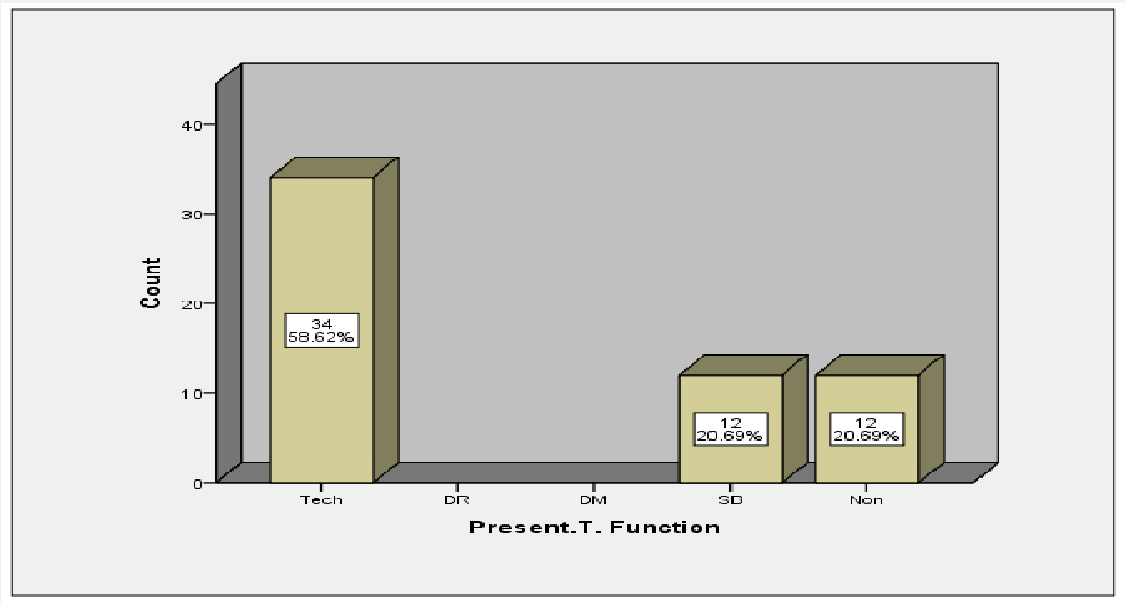

As illustrated in the figure above, the technical definition scored the highest frequency and percentage compared to the frequency of the style of the book ( SB). The frequency of the simple present in the description of the rationale and description of the method is low which shows that the simple present tense is not significant. Compared to Swales model ( $1990: 105$ ), the simple present tense shows a high frequency in general within the definition move of the Translator's Introduction which is comparable to the introduction move of the research article.

2- How many and what functions does the simple present tense express within the rationale move? To answer the second research question, the researcher analyzed the frequency and percentage of the functions expressed by the simple present tense within the rationale unit as shown by Figure 2 below.

As indicated in Table (2) below, the simple present tense frequented 40 times representing $93.02 \%$ to describe the rationale of selecting the book for the translation whereas non frequented 2 times recording $4.65 \%$. Which can be illustrated obvious by the chart below.

Table (2). frequency and percentage of functions of simple present tense within rationale.

\begin{tabular}{|l|l|l|l|l|l|l|}
\hline Rationale & Tech & DR & DM & SB & Non & Total \\
\hline Frequency & 0 & 40 & 1 & 0 & 2 & 43 \\
\hline Percentage & 0 & 93.02 & 2.3 & 0 & 4.65 & 100 \\
\hline
\end{tabular}

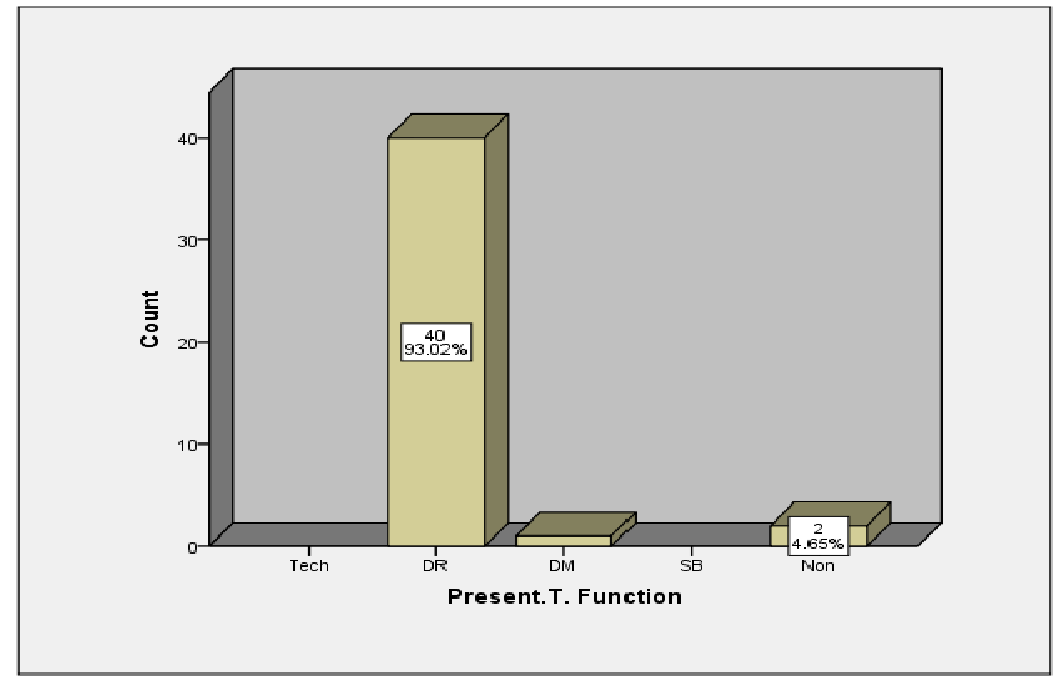

As seen in the above figure, the description of the rationale recorded the highest frequency which reflects the significance of the use of the simple present in expressing such function in comparison to non which frequented two times only. Heslot ( 1982 ) and Hanania \& Akhtar ( 1985 ) noted that simple present is the key tense in Introduction/ Discussion Sections which is so comparable to the present result .

3- How many and what functions does simple present tense express within the difficulties move? As presented in Table (3) below, it is clear that the simple present tense frequented 7 times recording $38.89 \%$ to indicate the difficulties the translators encountered since they thought of selecting a book for translation whereas non frequented 11 times reporting $16.11 \%$. 
Table (3).The frequency and percentage of functions of simple present tense within Difficulties move .

\begin{tabular}{|l|l|l|l|l|l|l|}
\hline Difficulties & Tech & DR & DM & SB & Non & Total \\
\hline Frequency & 0 & 0 & 0 & 7 & 11 & 18 \\
\hline Percentage & 0 & 0 & 0 & 38.89 & 61.11 & 100 \\
\hline
\end{tabular}

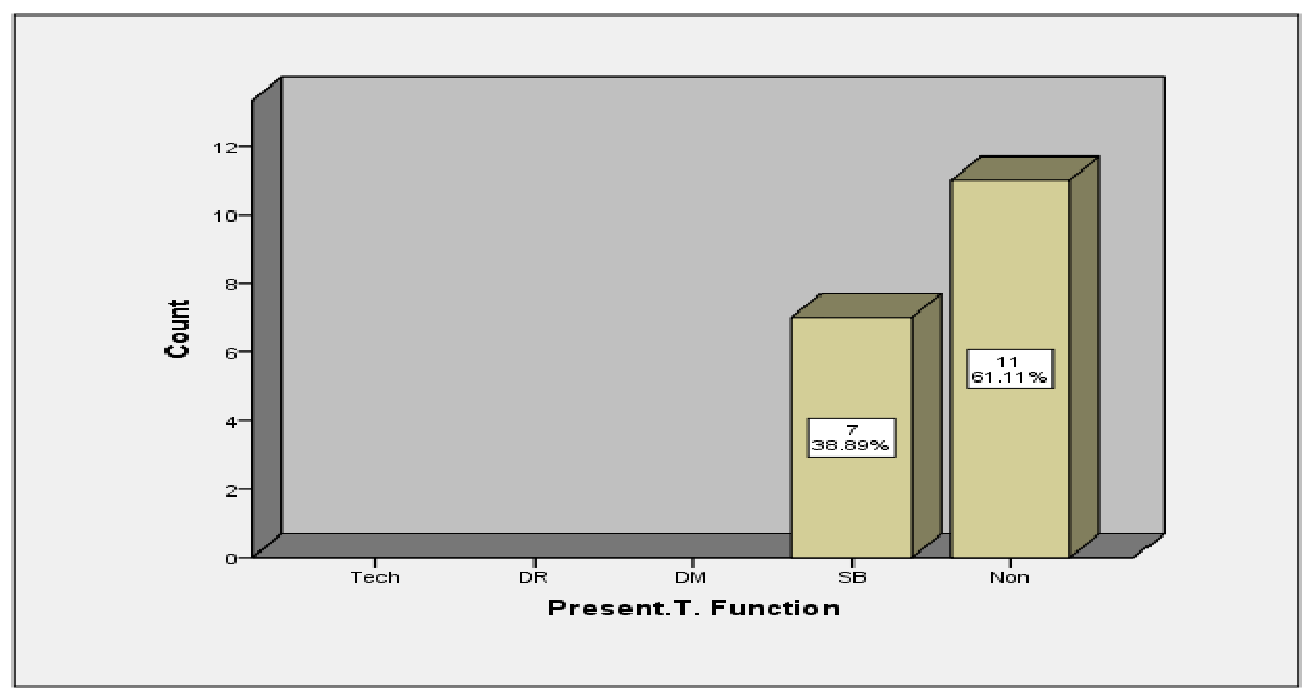

As shown by the figure above, it can be seen that non showed the highest frequency whereas the style of the book function registered only 7 which signifies the non - standardization, too. In comparison to Swales model ( $1990: 105$ ) the simple present tense shares the same low frequency when expressed the functions illustrated in table (3).

4- How many and what functions simple present tense expresses within the method move? As shown in Table (4) below, it is clear that the simple present frequented 20 times representing $46.51 \%$ to describe the characteristics of method of their translation whereas non frequented 23 times reporting $53.49 \%$.

Table (4). Frequency and percentages of the functions of simples present tense within Method Move .

\begin{tabular}{|l|l|l|l|l|l|l|}
\hline Method & Tech & DR & DM & SB & Non & Total \\
\hline Frequency & 0 & 0 & 20 & 0 & 23 & 43 \\
\hline Percentage & 0 & 0 & 46.51 & 0 & 53.49 & 100 \\
\hline
\end{tabular}

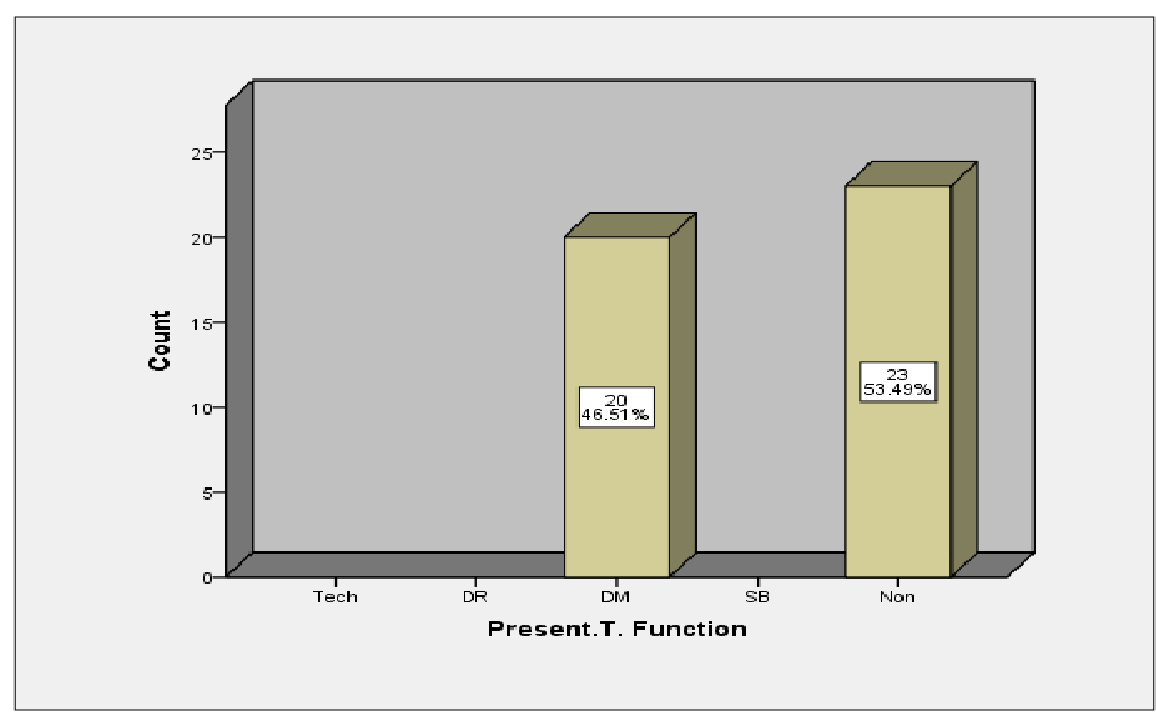

As can be shown in the figure above, the description of the method of the translation obtained $46.51 \%$ which is also a significant percentage and frequency indicating the importance of simple present tense in describing the characteristics of methods. However, a higher percentage was reported by non which signifies non standardization in the use and usage of simple present tenses within this move. Unlike the high frequency established by Heslot ( 1982 ) It is clear that simple present becomes prevalent in the description of the method in the current work. 
5- How many and what functions simple present tense expresses within the non move?

As seen in table (5) below, the frequency of the functions of simple present shows non occurrence with the frequency of 38 times and percentage o of $100 \%$.

Table (5). Frequency and percentages of functions of simple present within non move.

\begin{tabular}{|l|l|l|l|l|l|l|}
\hline Non & Tech & DR & DM & SB & Non & Total \\
\hline Frequency & 0 & 0 & 0 & 0 & 36 & 38 \\
\hline Percentage & 0 & 0 & 0 & 0 & 100 & 100 \\
\hline
\end{tabular}

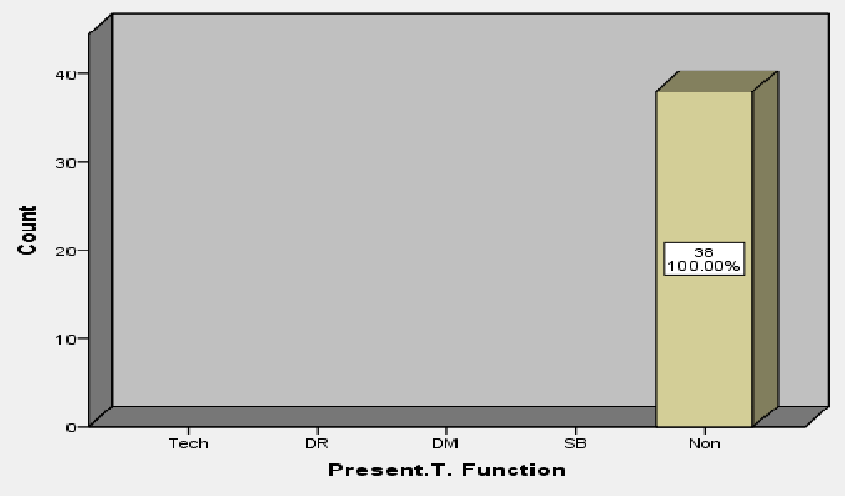

As seen, the figure above illustrates non repetition of the functions of simple present tense the matter which indicates how uses and functions vary among the investigated sample

6- How many and what functions does simple past express within definition move?

To obtain an answer for the question 6 of the research, the researcher identified the functions and analyzed them statistically as show in table (6) below.

Furthermore, the results indicated that simple past tense had certain uses in relation to and within moves. Concerning the definition move , simple past frequented 20 times representing $34.48 \%$ to state the historical back ground on translation difficulties relating to conceptual aspects within the definition move frequented 22 times reporting 37.93\%, whereas non frequented 16 times representing $27.59 \%$.

Table(6) Frequency and percentage of functions of simple past tense within Definition Move.

\begin{tabular}{|l|l|l|l|l|l|l|}
\hline Definition & HBG & AS & STA & DI & Non & Total \\
\hline Frequency & 20 & 0 & 0 & 22 & 16 & 58 \\
\hline Percentage & 34.48 & 0 & 0 & 37.93 & 27.59 & 100 \\
\hline
\end{tabular}

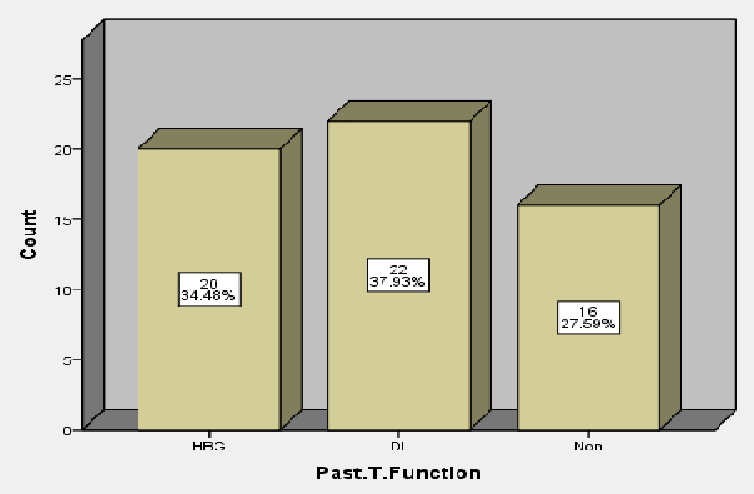

As represented in the figure above, simple past was used 20 times to state a Historical background of translation. Furthermore, simple past was used to express difficulties translators faced to understand some definitions. It is obvious that the past becomes prevalent in two functions only, namely the historical background (HBG) and difficulties indication (ID) while its use is zero in the action of selection ( AS ) and the steps adopted ( STA ). 
7- How many and what functions does simple past tense express within rationale move.

As presented in table (7) below, the recurrence of simple past tense reported the highest frequency to the action of selection. This indicates the significance of past tense within the rationale move used by translators when expressing the actions they took in the process of selecting the material to be translated .

Table (7). Frequency and percentage of functions of simple past tense within rationale move

\begin{tabular}{|l|l|l|l|l|l|l|}
\hline Rationale & HBG & AS & STA & DI & Non & Total \\
\hline Frequency & 0 & 31 & 0 & 0 & 12 & 43 \\
\hline Percentage & 0 & 72.09 & 0 & 0 & 27.91 & 100 \\
\hline
\end{tabular}

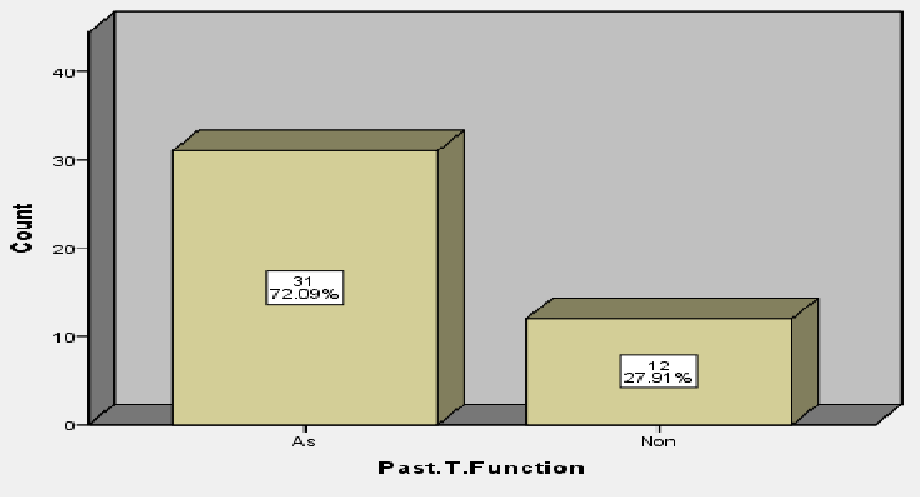

As illustrated in the figure above, it is clear that simple past frequented $72.09 \%$ to express the actions the translators they took to the select the material wanted to translate. It is observable that simple past is the key tense in expressing the actions taken to select the material under translation ( AS ), while its frequency in the historical background ( HBG ), steps adopted and difficulties indicated is too low.

\section{8- How many and what functions does simple past express within Method Move.}

As regards the method move, the results in table $(8)$ indicated the use of simple past with the frequency of 3 times representing $6.98 \%$ to indicate the action of the selection(AS) of the method to be used in the translation, whereas the use of the past frequented 37 times recording 86.05 to state the steps adopted ( STA) in the method of translation, and non frequented 3 times with the percentage $6.98 \%$.

Table( 8 )Frequency of functions of past tense within the method move.

\begin{tabular}{|l|l|l|l|l|l|l|}
\hline Method & HBG & AS & STA & DI & Non & Total \\
\hline Frequency & 0 & 3 & 37 & 0 & 3 & 43 \\
\hline Percentage & 0 & 6.98 & 86.05 & 0 & 6.89 & 100 \\
\hline
\end{tabular}

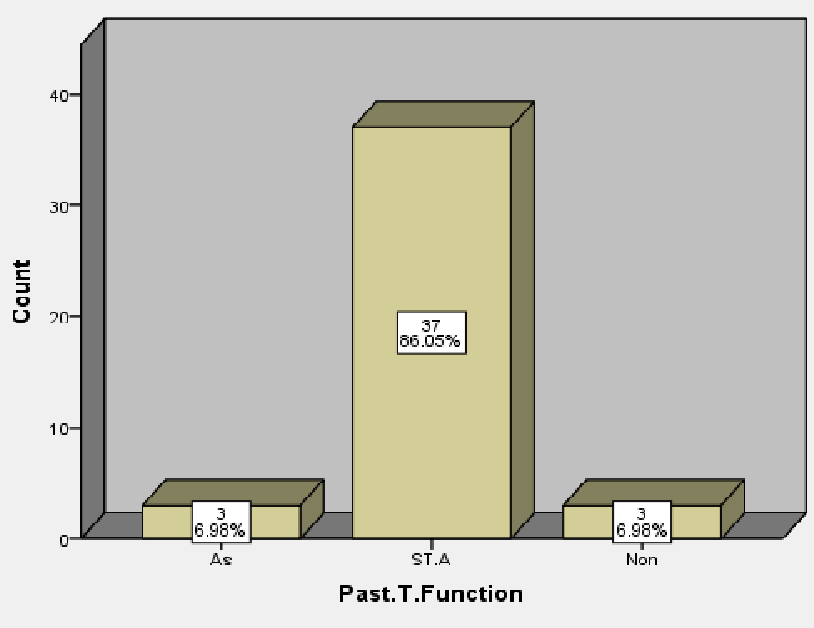

As can be seen in the figure above, the simple past tenses scored the highest percentage ( 86.05$)$ in stating the steps adopted in the method of translation which reflects the significance of such tense within the method 
move. Heslot ( 1982 ) \& Hanania \& Akhtar ( 1985 ) proved that past becomes prevalent in Methods which supports the current analysis of the prevalence of simple past tense in Method move notably the methodological steps adopted by the authors of Translator's introduction.

\section{9- How many and what functions does simple past express within difficulties move?}

To get an answer for question 9 of the research, the researcher presented below figure 9 which shows the frequency and percentage of functions expressed by the simple past within the difficulties move.

In relation to the difficulty move in table ( 9 ) below, the past simple frequented 18 times with the percentage of $100 \%$ to show the difficulties that faced the translation process.

Table ( 9 ). Frequency and percentage of functions of simple past within Difficulties Move.

\begin{tabular}{|l|l|l|l|l|l|l|}
\hline Difficulties & HBG & AS & STA & DI & Non & Total \\
\hline Frequency & 0 & 0 & 0 & 18 & 0 & 18 \\
\hline Percentage & 0 & 0 & 0 & 100 & 0 & 100 \\
\hline
\end{tabular}

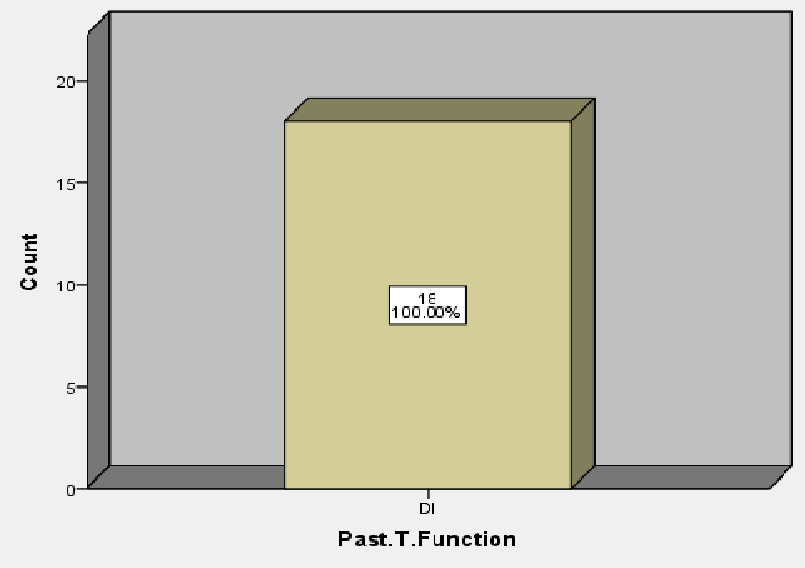

As can be seen in the figure above, the difficulties which encountered the translators during the translation process reported the highest frequency which is an indication of the significance of simple past tense within the difficulties move.

As shown by table ( 10 ) below, non frequented 38 times with the percentage of $100 \%$.

Table ( 10 ). Frequency and percentage of functions of simple past within non moves

\begin{tabular}{|l|l|l|l|l|l|l|}
\hline Non & HBG & AS & STA & DI & Non & Total \\
\hline Frequency & 0 & 0 & 0 & 0 & 38 & 38 \\
\hline Percentage & 0 & 0 & 0 & 0 & 100 & 100 \\
\hline
\end{tabular}

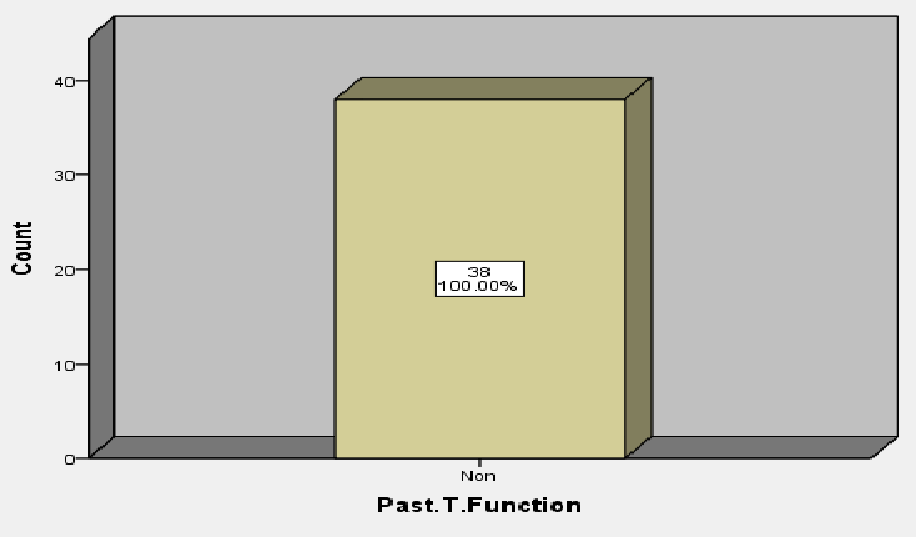

As indicated in the figure above, non frequented 38 times with the percentage of $100 \%$ to state non occurrence of the functions written above, Historical background ( HBG ) ,Action of Selection ( AS) ,Steps Adopted in translation ( STA) and the Difficulties which faced the authors. 


\section{8- Conclusion}

In conclusion, the above analysis of the tenses and their functions revealed that simple present and simple past tenses were used. The tables ( 11 ) and ( 12) inndicated the frequency and percentages of simple present and simple past tenses in 50 translator's introductions. As can be seen in table (11) below, simple present tenses was used 350 times reporting $100 \%$ the matter which signifies its importance . The results indicate that simple present tense expressed four functions including technical definition of translation, $(58.62 \%)$, the style of the book ( 20.69), rationale of selecting the material for translation, the difficulties translators face in general ( $38.39 \%)$ and description of the method of translation ( $46.51 \%$ ).

Table (11): Total of the frequency and percentage of present tense in all moves.

\begin{tabular}{|l|c|c|}
\hline Move & Frequency & Percentage \\
\hline Definition & 190 & 53.07 \\
\hline Rationale & 105 & 29.33 \\
\hline Method & 50 & 13.97 \\
\hline Difficulties & 13 & 3.63 \\
\hline Non & 0 & 0 \\
\hline Total & 358 & 100 \\
\hline
\end{tabular}

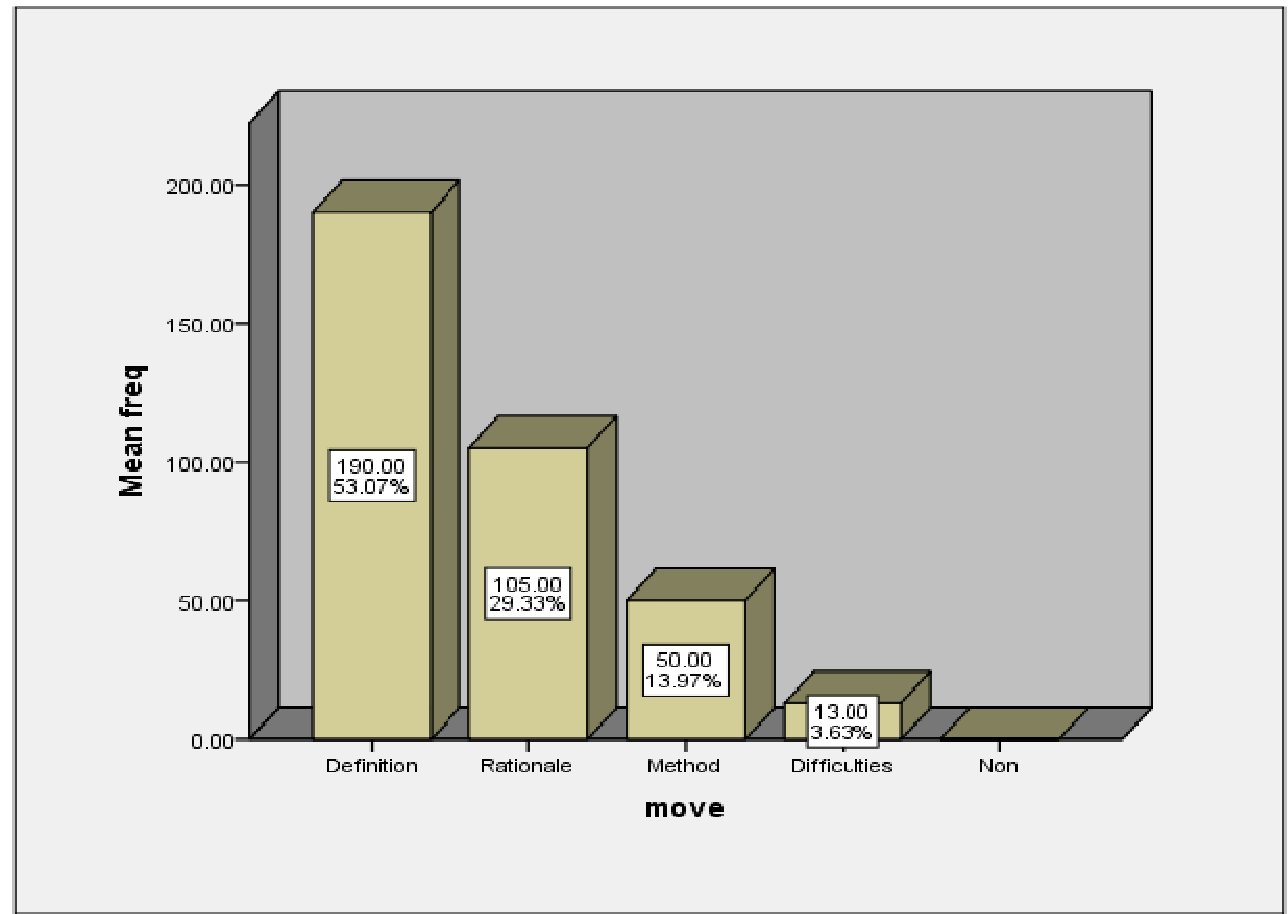

As can be seen in the figure above, there is a significant gradation in the frequency of simple present . When used to express technical definition of translation, the simple present frequented 190 times representing 53.7\%. The chart also indicates simple present scored a high frequency to express rationale of translation repeating 105 times . Furthermore, simple present recurred 50 times with the percentage of $13.97 \%$. It is worth mentioning that simple present, as can be seen above, repeated less than the other functions as it frequented 13 times only representing $3.63 \%$ However, figure 12 below shows a relatively more frequency of simple past in comparison to the figure 11 which presents the frequency of simple present .

Table (12): Total of the frequency and percentage of past tense in all moves.

\begin{tabular}{|l|c|c|}
\hline Move & Frequency & Percentage \\
\hline Definition & 172 & 37.39 \\
\hline Rationale & 82 & 17.83 \\
\hline Method & 170 & 36.96 \\
\hline Difficulties & 36 & 7.83 \\
\hline Non & 0 & 0 \\
\hline Total & 460 & 100 \\
\hline
\end{tabular}

As can be illustrated in the figure above, it is clear that simple past tense frequented 460 times representing $100 \%$. The simple past tense expressed various functions including Historical background on translations $(43.48 \%)$, difficulties relating to conceptual aspects which encountered the translators during the translation 
process ( 37.93) Action of Selection ( AS) 72.9 ), ( STA )steps adopted in the method of translation ( 86.5) Finally other types of difficulties related to deconstruction of the text.

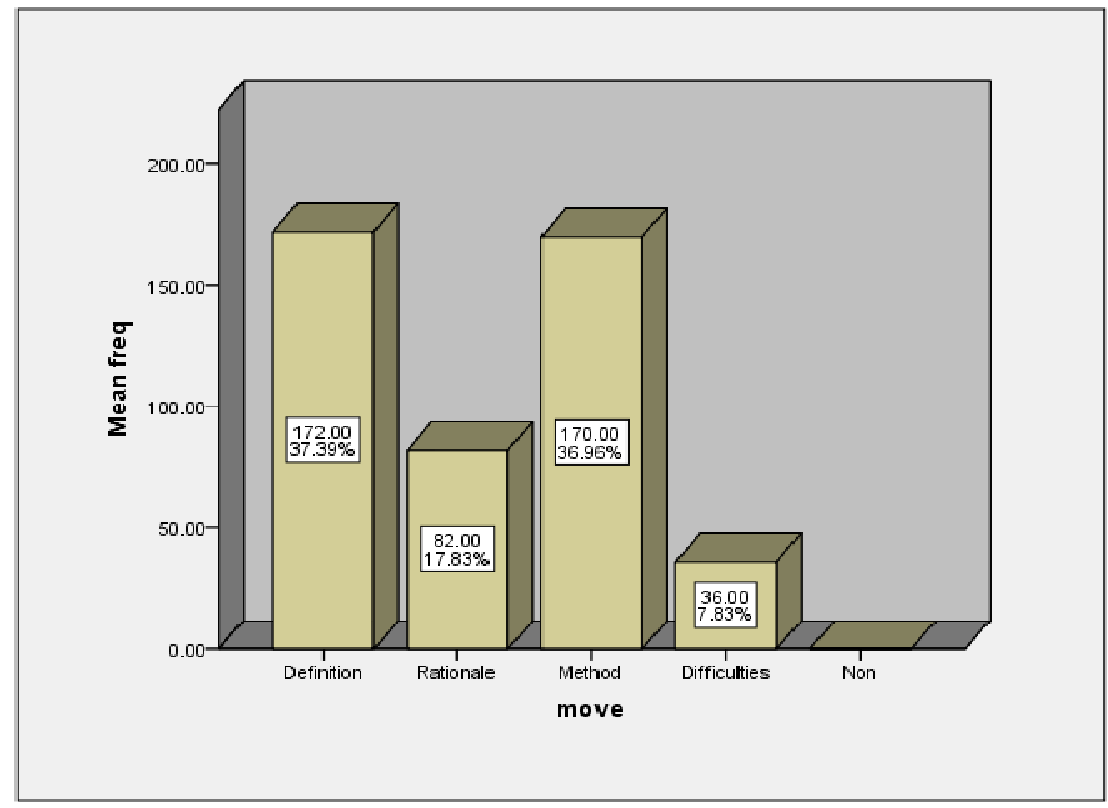

As can be shown in the figure above, simple past frequented 172 times within the definition move scoring the highest rate compared to its use within the next moves including rationale ( 82 times ) and difficulties (36 times ). However, compared to its frequency within the definition move, it is clear that simple past recurred 170 times. It is obvious that the distribution of tenses corresponds to Swales Model in terms of using simple present and simple past tenses in method move where frequency of present tense is low while the frequency of past tense is high as seen in tables ( 11 ) and (12) respectively and as show in the distribution of tenses in Swales ( 1990 ) Model . It is worth mentioning that moves of translators' Introduction, which consists of definition, rationale, method and difficulties ( Nasir, 2017 ), differ from moves of research articles found in research articles that is why frequency of tenses can be compared method moves only as it is the only common move.

Summing up tables 11 and 12 , it is obvious that simple present tense becomes prevalent within the definition move and used to express technical definition and style of the book reporting 53.07\% where simple past tense represented $37.39 \%$ only and tend to express two functions which are Historical background ( HBG ) and difficulties which faced the authors to understand the definition. In addition, it seems that the use of simple present in rationale move is popular than the simple past in rationale as indicated in the tables above. Again, the frequency of simple past in the method move is dominant than the frequency of simple present in the same move. Finally, it is clear that simple past is the key tense to express the difficulties which encountered the authors in the translation process.

Generally speaking, simple present and simple past tenses express various functions within the moves.

The researcher recommends that another investigation to be conducted on how such tenses functions correlate with steps which form the rhetorical moves .

\section{References.}

Adamczewski, H. ( 1982 ) Grammaire Linguistique de I'anglais. Paris, Armand Colin.

Ahmed, K. A. ( 2011 ) Genre Analysis: Investigation of MA Dissertation Abstracts.Unpublished Ph.D. thesis. University of Gezira.

Barber C.L. ( 1962 ) Some Measurable Characteristics ofModern Scientific Prose. In Behre F. (ed ) Contributions to English Syntax and Philology . Stockholm: Almquiost @Wikwell. Pp21 - 43.

Biber D., Conrad S., \& Reppen R. ( 1998 ) Corpus Linguistics: Investigating Language Structure and Use Cambridge: Cambridge University Press.

Bazerman,C. (2004) Speech acts, genre, and activity systems . Mahwa, New Jersy: Erlbaum.

Bhatia, V.K. (1993) Analyzing genre: Language use in professional settings . Harlow.

Bhatia, V.K. (1994). Cognitive structuring in legislative provisions. London.

Bhatia,V. (2004) Words of Written Discourse :A genre-bases view(2004).London: Continuum.

Chodurova, K. ( 2010 ) Distribution of Tenses in Newspaper Language.Bachelo thesis.

Christopher, GLEDHILL ( 2009a ) Colligation and the Cohesive Function of Present and Past Tense in the Scientific Research Article .In David Banks ( red ), Les Temps et les Textes de specialite . Paris. I'Harmattan. Pp $65-84$. 
Culioli, A. (1999) Pour une Linguistique de l'enonciation. Paris, Gap: Ophtys.

Cotterill, J. (2002) Language in the legal processes. Hampshire, United Kingdom: Palgrave.

Coulthard, M. (1992). Forensic discourse analysis (1992). London.

Coulthard, M. (2005a) Some forensic applications in descriptive linguistics. Website.

Devitt, A. j. ( 1991 ) Intertexuality in tax accounting. In Bazerman@ J. Paradis (Eds ), Texual dynamics of the profession ( pp. $336-357$ ). Madison: University of Winsconsin press.

Dudley - Evans, A. and Henderson, W (1990). The Organization of Article Introductions : Evidence of Change in Economics in Writing . In W.Henderson and A.

Elvan Eda, T. ( 2008 ) A corpus - based Analysis of Genre Specific Discourse of Research: The PhD thesis and The Research Article in ELT . Middle East Technical University, PhD.

Firth J.R. ( 1935 ) The Techniques of Semantics, Transactions of the Philological Society. pp 36- 72.

Firclough, Norman (2001). Language and power. Longman.

Fairlough, Norman (2006). Discourse analysis and social change . Polity.

Gerbert M. ( 1970 )Besonderheiten der Syntax in der Technischen Fachsprache des Englischen. Berlin: Halle.

Gibbons, J. (2003). Forensic linguistic: An introduction to language in the justice system . London: Blackwell.

Gledhill, C. ( 1995 ) Collocation and Genre Analysis, Zeitschrift Fur Anglistik und Amerikanistik 53, 1/1 :11 36.

( 2000a ) Collocations in Science Writing .Tubingen, Gunter Narr.

( 2000b ) The Discourse Function of Collocation in Research Article Introductions. English for Specific Purposes, 19/2:115-135.

Goodrich, P. ( 1987 ) Legal discourse . London. Macmillan.

Halliday M.A.K. \& Hasan R. ( 1976 ) Cohesion in English. London: Longman.

Halliday M.A.K.\& Martin J. ( 1993 ) Writing Science: Literacy and Discursive Power . London: Falmer Press.

Hanania E.A.S. \& Akhtar K. ( 191985 ) Verb Form and Rhetorical Function in Science Writing : A Study of M. Sc. These in Biology, Chemistry, and Physics, English for Specific PurposesVol.4: 49 - 58.

Halliday, M.A.K., McIntosh, A. and Strevens, P. ( 1964 ). The Linguistic Sciences and Language Teaching. The English Language Book Society and Longman Group ltd., London.

Hawes T.\& S. Thomas. ( ( 1997 ) Tense Choices in Citations, Research and Teaching of English 31: 394-414.

Heslot, Jeane ( 1982 ) Tense and other Indexical Markers in the Typology of Scientic Texts in English .In Hoedt, Jorgen ( ed ) Pragmatics and LSP : Proceedings of the third European symposium on LSP, Copenhagen, August 17 - 19, 1981. Copenhagen School for Economics , 83-104.

Hyland, k. ( 2004 ) Genre and sceond language writing . Anarrbor: University of Michigan press.

Hoey, M. ( 2005 ) Lexical Priming: A new Theory of Words and Language. London: Routledge.

Hunston, S \& Francis, G. ( 2000 ) Pattern Grammar. Amestrdam: John Benjamins.

Jalilifar, A. ( 2010 ) Research Articles Introductions :Sub -disciplinary Variations in Applied Linguistics. The Journal of Teaching Language Skills.( JTLS) Vol.2, No.2, Ser. 16/4.

Jitra M \& Nutprapha, K.D ( 2016 ) Astudy of Tenses Used In English Online News Website. International Journal of Research -Granthaalayah.Vol4, $248-258$.

Lackstrom. J. E., Selinker, L. \& Trimble, L. ( 1973 ) Technical rhetorical principles and grammatical choice, TESOL Quarterly 7, $127-136$.

John E. Joseph ( 2004 ) Language and Identity. Palgrave Macmillan.

Lakie,I. ( 2010 ) Analyzing Genre " Research Introductions in Economic". Institute of Foreign Languages, University of Montenegro, JOLIE, 3/2010.

Oster S. ( 1981 ) The Use of Tenses in Reporting Past Literature in EST. In L. Selinker, E. Tarone \& V. Hanzeli ( eds ), English for Academic and Technical Purposes: Studies in Honor of Louis Trimble. Massachussets: Newbury House, pp $76-90$.

Mahjoobeh Abarghooeinez \& Shahla Simi ( 2015 ) Analyses of Verb Tense and Voice of Research Article Abstracts in Engineering Journals. International Letters of Social and Humanistic Sciences. Vol. 47, pp 139 $-139$

Malcolm L. ( 1987 )What Rules Govern Tense Usage in Scientific Articles? English for Specific Purposes Journal $6 / 1: 31-43$.

Mohamed Alzein, A.M. ( 2002) Alwageez fisharh alsiyaq( Sudanese court judgments in personal cases) . Khartoum: International printing press.

Nasir, S. ( 2017 ) Genre Analysis: Investigation of Rhetorical Moves in Translator's Introduction, International Journal of English Language. Literature and Translation Studies 4/4 ( 165 - 174 )

Nwogu, N.k. ( 1997 ) The Medical Research Paper : Structure and Functions . English For Specific Purposes, 16 (2), $119-138$.

Pezzini, O. ( 2006 ) Genre Analysis and Translation: An Investigation of Abstracts of Research Articles in Two Languages . Universidade Federal de Santa Catarina : Available at ornellapezzini@terra.com.br. 
Salager - Meyer F. ( 1992 ) A Text Type and Move Analysis Study of Verb Tense and Modality Distribution in Medical English Abstracts, English For Specific Purposes 11/2: 93 - 114.

Suryani, B. ( 2007 )Genre Analysis of the Translated English Abstracts .

Thesis, Applied Linguistics Study, Graduate Program of the State University of Seamarang.

Salkie, R. ( 1995 ) Text and Discourse Analysis .London: Routledge.

Swales, J. ( 1981 ) Aspects of Article Introductions . Birmingham, Languages Studies Unit, The University of Aston at Birmingham.

Swales, J. (1986). Citation Analysis and Discourse Analysis . Applied Linguistics 7(): 39-56.

Swales, J. (1990). Genre analysis: English in academic and research settings. Cambridge: Cambridge University press.

Swales, J. (2004). Research Genres: Explorations and Applications . Cambridge: Cambridge University Press.

Swales, J. M. and Feak, C. B. ( 1994 ) Academic Writing for Graduate Students . A course for Non native Speakers. Of English. Michigan: University of Michigan Press.

Tiersma,P.M. ( 1993 ). Linguistic issues in the law . Language:69, 133 - 137.

White H. D. ( 2004 ) Citation Analysis and Discourse Analysis Revisited , Applied Linguistics 25/1:89-116 